\title{
A Conceptual Framework for the Acceptance of Drones
}

\author{
Johnny Chamata \\ Faculty of Business, Curtin University, Malaysia \\ Email: johnny.chamata@gmail.com \\ Jonathan Winterton \\ Faculty of Business and Law, Taylor's University, Malaysia
}

\begin{abstract}
The literature on the public acceptance of unmanned aircraft, aka drones, is scarce and undeveloped. This is evident in the absence of theoretical and methodological substantiality in existing research. This research paper suggests a conceptual model for predicting the public acceptance of unmanned aircraft. This was accomplished by systematically reviewing previous literature on the public acceptance of genetically modified food and nuclear energy. Results of the review revealed that behavioral models such as TRA and TAM, when include concepts from risk theory, can provide the desired model. The model consists of five constructs namely: intention to purchase/use, attitudes towards using, perceived benefit, perceived risk, and perceived control. Future research is required to further develop the proposed model relevant for the context of drones' acceptance.
\end{abstract}

Keywords: public acceptance, civil drones, unmanned aircraft, conceptual framework, systematic review.

\section{Introduction}

Amidst successive economic crises, represented in job and business losses, civil drones $^{\star}$ hold the promise of boosting the economy, as recent reports claim. Economic effects are tangible and the industry is forecasted to generate tremendous revenues and jobs. In the United States and the European Union, there are predictions that the industry will generate between $\$ 80-\$ 100$ billion dollars and thousands of jobs over a course of a decade or so (AUVSI 2017; EU Business 2014; Jenkins and Vasigh 2013; Mills 2016).

In addition, UAS technology is on the verge of being integrated into hundreds of commercial and civil applications (Chamata 2017; LeMieux 2014), and will soon replace alternative technologies, i.e. helicopters, in various applications (Sebbane 2012). Recent advances have shown that UAS are extremely useful in benevolent activities such as search and rescue (Molina et al. 2012), disaster management (Murphy et al. 2008), and ambulancing (Daily Mail 2014).

Nonetheless, several sociotechnical issues are instigating public outrage towards the technology suspected to cause a delay in UAS adoption (Clarke 2014a,b,c; Chamata 2016). And, whereas, the literature broadly discusses these issues, it rarely [and insufficiently] studies factors which influence public acceptance, i.e. Clothier et al., 2015. Several non-academic reports exist however are not based on theory and employ inappropriate research methods yielding merely descriptive results (Bracken-

\footnotetext{
* Alternative terms: unmanned aerial systems (UAS), unmanned aerial vehicles (UAV), remotely piloted aircraft (RPA), unmanned aircraft ... etc.
} 
Roche et al. 2014; Eyerman et al. 2013; Macsween-George 2003; Murray 2012).

Thus, we are before a need to employ a theory or model for predicting public acceptance of unmanned aircraft. However, technology acceptance theory, e.g. Davis' TAM, is being widely criticized in the literature for being employed excessively and superficially in research (Bagozzi 2007; Silva 2007; Hwang et al. 2015). Researchers, as Bagozzi (2007) describes, are failing to add substantial meaning to existing theory. In addition, technology acceptance theory is mainly employed in IS-related research and in organizational setting, and does not discuss risk as an influential factor which is strongly present in the UAS literature. Therefore, the authors respond to these enquiries and pursue the development of a new model relevant for predicting the public acceptance of unmanned aircraft.

In identifying the initial traits of the desired model, this research will rely on performing a systematic review of the literature on the public acceptance of genetically modified food [GMF] and nuclear energy. GMF and nuclear energy have long been known for creating safety and security concerns, similar to the aforementioned concerns associated with drones. However, public concerns about privacy remain dronespecific.

The review will scrutinize the theories, concepts, and relationships, employed in previous research. Based on the apparent themes and patterns, a model for the acceptance of unmanned aircraft will be proposed. Our choice of these technologies is due to the extensive research done on the public acceptance in both contexts, and because they have been controversial as is the case for unmanned aircraft.

\section{Methods}

A systematic review of research on the public acceptance of GMF and nuclear energy was conducted following the PRISMA guidelines which include the identification of: information sources, search criteria, and study selection criteria (Liberati et al. 2009). PRISMA protocols are well supported in the literature and employed in several similar studies (Cameron et al. 2014; Khong et al. 2015; Pidgeon et al. 2015).

\subsection{Information Sources}

Studies were searched over several electronic databases such as those of Curtin University, Web of Science, and Scopus. Nonetheless, Scopus was excluded later because it returned unreasonable numbers of journal articles [e.g. $7000+]$ which were irrelevant to the search criteria described below. Thus, the search continued with the two other databases. Occasionally, when full-text articles were not available on Curtin University and Web of Science databases, other sources were sought [e.g. Google Scholar].

\subsection{Search Criteria}

The search targeted relevant material published between years 2000 and 2017 inclusive. An initial search of the aforementioned databases enquired the keywords 'public acceptance' and 'public perception'; which yielded the same search results. Therefore, only one keyword was retained, 'public acceptance'. Then filters were applied to search for keywords in titles of articles only. Search on both Curtin University and Web of Science databases yielded 328 and 180 articles, successively. Before download, articles were screened to ensure that they were written in English and that the titles included terms related to GMF and nuclear energy. Only articles abiding by these criteria were downloaded yielding 64 articles evenly divided between public acceptance of GMF and nuclear energy. Subsequently, duplicate articles were removed and only 53 papers were qualified for the study selection phase. 


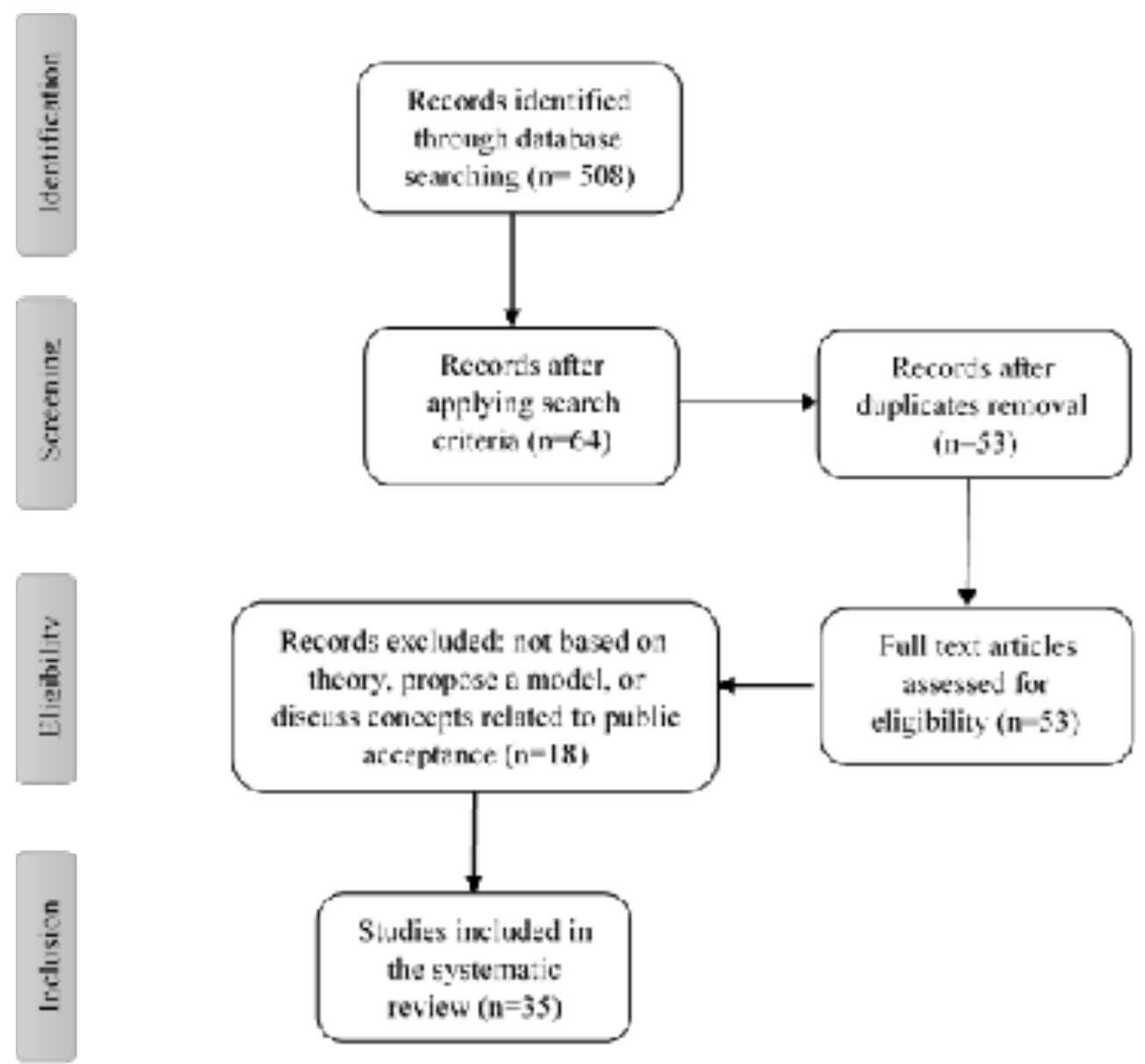

Fig. 1: PRISMA procedures - Adapted from Liberati et al. 2009

\subsection{Study Selection}

Eligibility criteria for the selection of relevant journal articles were applied over four stages. Initially, articles were divided into categories based on the subject: genetically modified foods and nuclear energy. Studies which met the following criteria, were considered eligible: that the study is based on theory, proposes a model, OR discusses concepts, related to public acceptance. Once these criteria were met, a study would be examined for the identification of proposed hypotheses. Research which was supported by theory, proposed concepts, or which hypothesized relationships, was retained for its relevance to the aim of this systematic review of developing a model of UAS technology acceptance. Study selection criteria, thus, resulted in the exclusion of 18 articles, and only 35 articles were included in the systematic review.

\section{Findings}

\subsection{Theories and Frameworks Underpinning Research}

Articles which employed existing theory or proposed frameworks were twenty-one. Both the theories and models proposed constructs commonly employed in technology acceptance 
research. Most employed was risk theory, thirteen studies either studied the influence of perceived risk on public acceptance (Chao-Jun et al. 2013; Costa-Font 2013; Frewer et al. 2004; Jenkins-Smith et al. 2011; Liu et al. 2008; Siegrist et al. 2007; Tsujikawa et al. 2016; Veeman et al. 2005; Visschers and Siegrist 2013; Yang et al. 2013), or proposed external variables which influence perceived risk (CostaFont and Gil 2012; Siegrist 2000; Siegrist et al. 2008]. Risk theory is prominent in investigating public acceptance, and relies on perceived risk as a sole indicator (Bettman 1973; Fischhoff et al. 1978).

Fishbein's attitude model, later developed to become the theory of reasoned action [TRA], was employed in four studies which either aimed at extending the attitude model (CostaFont et al. 2008; Costa-Font and Gil 2009], or predicting public acceptance (Costa-Font and Gil 2012; Moon and Balasubramanian 2001]. The attitude model proposes that attitudes towards using a technology or product are the result of summed and unseparated beliefs (Ajzen and Fishbein 1969). Fishbein's model is advantageous, compared to risk theory, as it gives the opportunity of investigating several beliefs as determinants of attitudes [e.g. acceptance] rather than only perceived risk.

The discrete choice model, developed by Thurstone and Marschak, was used in two articles investigating public attitudes towards the use of specific applications (Hossain et al. 2003) and the general intention to use a technology (Onyango and Schilling 2004). The discrete choice model is based on a dichotomous choice; the consumer is given the option to choose between two options only. For instance, they are enquired to show preference of a technology [e.g. UAS vs. Helicopter] or a response [e.g. Yes/No] over another. Unlike risk theory, the discrete choice model was shown to be flexible to integrating additional concepts or determinants of technology acceptance.

The dual process theory proposes two paths of probing public acceptance: the first is systematic and proposes that highly motivated consumers will cognitively analyze the benefits associated with [a technology] and then decide whether to accept or reject it. The second path is heuristic, and proposes that consumers with low motivation, to accept a product, are more likely to depend on government or expert opinion to make decisions (Chaiken et al. 1989). This theory, usually employed in political science, was used in Huang et al.'s (2010) research which studies several factors that influence public perception.

Truelove and Greenberg (2013) employed the theory of behavior change to investigate the factors influencing the public acceptance of nuclear power. The theory of behavior change proposes that the cognitive assessment of a technology relies on a consciousness raising process. The theory states that people at a preconsciousness stage are usually unwilling to use a technology, whereas those who reached consciousness consider using it in the future (Prochaska et al. 2008). This agrees with Yankelovic (1991) who proposes that public 
acceptance is achieved over three stages: consciousness raising, establishing debates, and judgment.

Fishbein's attitude model, though ranking second in frequency of use, is found relevant to the purpose of this research because it provides a broader explanation of technology acceptance. Nonetheless, a merge of risk theory to the attitude model would be beneficial as it provides bases for the risk component often addressed in UAS literature. Thus, in this research, the theory of reasoned action and risk theory will be considered as theoretical foundations. The remaining theories are not selected because they are deemed irrelevant to the context of this research.

\subsection{Summary of Significant Concepts and Relationships}

Several concepts were employed in the theories and frameworks of the reviewed studies. That is in addition to various categories of external or situational variables. Nonetheless, the pursue of core concepts which have a direct influence on public acceptance was prioritized because: (1) the focus of the research is to explore the direct antecedents of technology acceptance, and (2) the influence of external variables is usually mediated by beliefs and add too little to the model's predictive power (Hwang et al. 2015; Legris et al. 2003). Yet, the influence of external variables is presented herein. Core concepts which were more frequently employed in research on GMF and nuclear energy are: perceived risk, perceived benefit, perceived control, attitudes towards using and the intention to use/purchase a technology.
Combining perceived risk and perceived benefit was the major theme; they were employed together in 23 articles. Both beliefs were related to knowledge and/or trust as influential variables in 13 studies (Costa-Font et al. 2008; Costa-Font and Gil 2009, 2012; Truelove and Greenberg 2013; Hossain et al. 2002; Hossain et al. 2003; Huang et al. 2010; Lucht 2015; Magnusson and Hursti 2002; Moon and Balasubramanian 2001; Rollin et al. 2011; Siegrist 2000, 2008; Siegrist et al. 2007; Siegrist et al. 2008; Visschers and Siegrist 2013; Yang et al. 2013). Less frequently, these studies integrated variables such as information availability, safety attitudes, enthusiasm about the technology, willingness to learn, product characteristics, norms, and values. The direct influence of knowledge on attitudes was addressed once (Visschers and Wallquist 2013).

The influence of sociodemographic variables on the core beliefs was also studies in several occasions. For instance, age, gender, education, income, and political views were hypothesized to influence a person's beliefs about both genetically modified foods and nuclear power (Costa-Font and Gil 2012; Hossain et al. 2002; Jenkins-Smith et al. 2011; Onyango et al. 2004; Rollin et al. 2011; Truelove and Greenberg 2013). Direct effects were considered on perceived risk (Yang et al. 2013; Jenkins-Smith et al. 2011) and attitudes (Kim et al. 2013), respectively. In two studies, the influence on perceived risk/benefit/control (Siegrist et al. 2008); and on perceived risk and 
perceived control (Veeman et al. 2005), was considered.

In 17 out of the 23 studies, the influence of perceived risk and perceived benefit towards attitudes was considered. Additionally, in 3 studies (Costa-Font et al. 2008; Costa-Font and Gil 2009; Frewer et al. 2013), the mediating effect of attitudes, between perceived risk/ benefit and intention, was hypothesized. The direct relationship between perceived risk/ benefit and intention was addressed in one study (Siegrist et al. 2007). It is noteworthy that the influence of perceived control, along with perceived risk/benefit, on attitudes, was considered once only Magnusson and Koivisto Hursti 2002).

Less frequently, perceived risk and perceived benefit were considered separately. Perceived risk had an influence on attitudes (Frewer et al. 2004; Onyango and Schilling 2004; Costa-Font 2013), whereas attitudes mediated the influence of perceived risk, in several studies (Basaran et al. 2004; Sun et al. 2016]. The influence of perceived benefit on attitudes was studied once (Costa-Font and Gil 2012).

\section{Discussion}

From the above, it is evident that concepts are related as follows: sociodemographic, political, and psychological, external variables have influence on three main beliefs; perceived risk, perceived benefit, and perceived control. The beliefs, in turn, have a direct influence on attitudes which mediate their effect on intention; whereas, only perceived risk and benefit are directly associated with intention. Thus, the model may be depicted as in Fig.2 below.

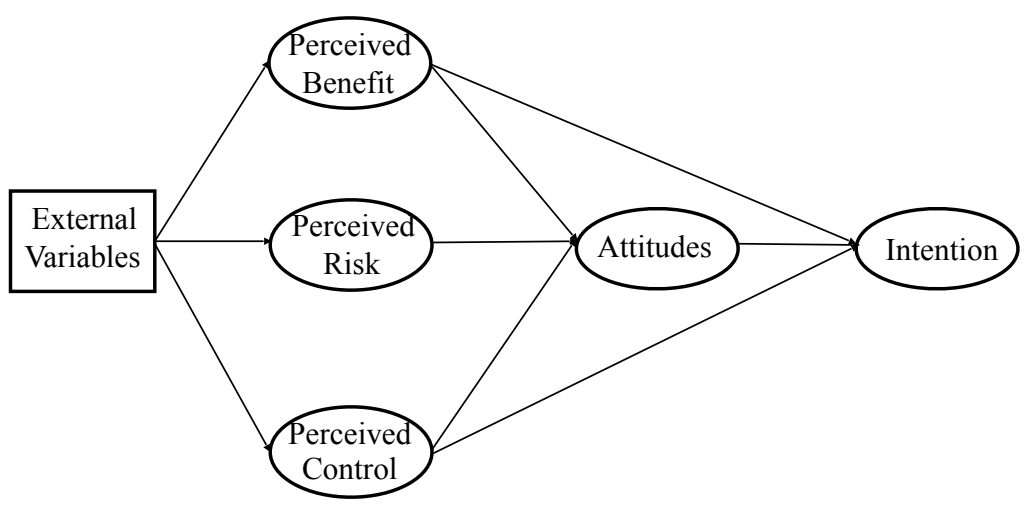

Fig. 2: Model extracted from the review

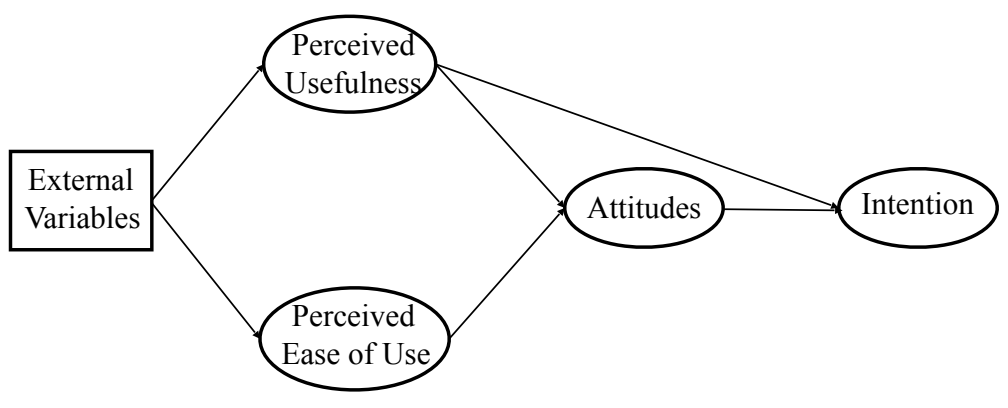

Fig. 3: Technology Acceptance Model Adapted from Davis et al. (1989) 
From a structural view, the inductive model resembles Davis et al.'s (1989) technology acceptance model (TAM) [compare Figs. 2 \& 3]. The resemblance is not surprising, as also TAM was based on the theory of reasoned action. However, the inclusion of perceived risk is novel and was rarely introduced in previous TAM studies. One must also note that several conceptual differences may exist between the inductive model and TAM. For instance, perceived control in the public context does not reflect self-efficacy as proposed by TAM, at this early stage of UAS adoption, as it is assumed that respondents had no experience flying drones. Instead it reflects the concept of controllability (control over use) as per several prominent authors (Bandura and Wood 1989; Fischhoff et al. 1978; Otway and Von Winterfeldt 1982). As well, whereas perceived usefulness in TAM is concerned with the benefits information systems provide to users, herein drones rather represent several [personal and national] socioeconomic benefits. Whereas, the concept of attitudes towards using may be similar to previous conceptualizations, purchasing intention should be defined differently to provide a broader coverage of people's intent.

The concepts extracted from the systematic review are relevant to topics discussed in UAS literature. For instance, concepts of perceived benefit, perceived risk and perceived control are discussed as influential factors of the public acceptance of drones (Cavoukian 2012; Clothier et al. 2015). Similarly, willingness [or intention] to use UAS was addressed in the context of transportation (Macsween-George 2003; Tam 2011). Thus, the inductive model is relevant to address UAS acceptance from various facets. Such relevance to contemporary issues in research on unmanned aircraft has several implications on the literature. For instance, introducing the concept of perceived benefit in a more salient manner promotes UAS technology as having the potential of being useful rather the current research more often discussing the risks associated with it (Clarke 2014a,b,c; Elias 2012). Similarly, perceived control was rarely explicitly discussed in the literature, except in the form of alerting the public (through SMS and banners) prior to UAS flights in nearby airspace (Cavoukian 2012). Introducing the perceived control concept sheds the light on its importance in alleviating public concerns (e.g. perceived risk), and should instigate more focus on its study in future research. Furthermore, proposing these concepts provides a broader interpretation of the public acceptance of drones, rather than the existing research focusing on perceived risk as a sole determinant (Clothier et al. 2015).

\section{Conclusion}

This research was based on the need of literature for a theory or model capable of explaining the public acceptance of drones. Current research mainly discusses public concerns or the operation and regulations of drones, however, it does not constitute any theoretical substantiality. The authors of this research paper was motivated to develop a 
theory or model. By means of systematic review, the authors explored the literature on the public acceptance of genetically modified foods and nuclear energy, for being controversial technologies as unmanned aircraft are considered today. The systematic review revealed that five core constructs may be capable of predicting the public acceptance of drones. The constructs accurately express current debates in UAS literature which include public concerns [e.g. perceived risk], advantages of the technology [e.g. benefits] (Clarke 2014c; Clothier et al. 2015), control over use in nearby airspace (Cavoukian 2012), public attitudes (Clothier et al. 2015), and intention to use (Macsween-George 2003; Tam 2011).

\subsection{Research Implications}

This study establishes for future research movement similar to that initiated after the rise of the technology acceptance model (TAM) in the 1980s. The UAS literature is in imperative need for development, and a huge gap exists between the efforts exerted by the industry and the academic research movement. This research paper contributes to the academic effort that should be done in this field, and to building the body of knowledge. The study is also the first which proposes a conceptual framework for predicting the public acceptance of drones, which encourages for further cumulative theoretical and empirical work to further understand public acceptance in this context. The research also answers urgent academic enquiry (Bagozzi 2007; Hwang et al. 2015; Silva 2007) for diverting from the TAM paradigm. Over four decades, researchers have not done any significant conceptualization to technology acceptance theory, but were stuck in merely assessing the influence of several external variables (Bagozzi 2007; Hwang et al. 2015). Such effort allows for integrating additional concepts to the model in the future, in accordance with emergent issues in the literature.

\subsection{Research Limitations and Future Directions}

Like any research, this paper is not left without limitations. The current paper merely explored the literature in pursue of a conceptual model, however the proposed model is not fully developed yet. Future research may further adapt the proposed concepts to the drones' context. Additionally, the research did not discuss in detail the influence of external variables, which may be useful in obtaining information about how certain sociodemographic variables, for example, may moderate public attitudes or purchasing intention. Such information is useful for marketing drones as it reflects the geographical and personal preferences of potential users.

\section{Acknowledgments}

This research is funded by the Curtin Malaysia Postgraduate Research Scholarship (CMPRS) scheme. The authors would like to thank Dr. Ahmed Rageh for his comments on the methods employed in this research. 


\section{References}

Ajzen, Icek, and Martin Fishbein. 1969. "The Prediction of Behavioral Intentions in a Choice Situation." Journal of Experimental Social Psychology 5 (4):400-416. https:// doi.org/10.1016/0022-1031(69)90033-X.

AUVSI. 2017. "Small Businesses Receive Majority of Waivers Under FAA's Small UAS Rule." Helis. 2017. http://www.helis.com/ database/news/drone_part107.

Bagozzi, Richard. 2007. "The Legacy of the Technology Acceptance Model and a Proposal for a Paradigm Shift." Journal of the Association for Information Systems 8 (4):244-54. https://doi.org/Article.

Bandura, Albert, and Robert Wood. 1989. "Effect of Perceived Controllability and Performance Standards on Self-Regulation of Complex Decision Making." Journal of Personality and Social Psychology 56 (5): 805-14. https://doi.org/ 10.1037/0022-3514.56.5.805.

Basaran, P, B Kilic, H Soyyigit, and H Sengun. 2004. "Public Perceptions of GMOs in Food in Turkey: A Pilot Survey." Journal of Food, Agriculture \& Environment 2 (3\&4): 25-28.

Bettman, Jr James R. 1973. "Perceived Risk and Its Components: A Model and Empirical Test." Journal of Marketing Research 10 (May):184. https://doi.org/ 10.2307/3149824.

Bracken-Roche, Ciara, David Lyon, Mark James Mansour, Adam Molnar, Alana Saulnier, and Scott Thompson. 2014. "Surveillance Drones: Privacy Implications of the Spread of Unmanned Aerial Vehicles (UAVs) in Canada."

Cameron, Miriam PI, Robin Ray, and Sabe Sabesan. 2014. "Physicians' Perceptions of Clinical Supervision and Educational Support via Videoconference: A Systematic Review." Journal of Telemedicine and Telecare 20 (5):272-81. https://doi.org/ 10.1177/1357633X14537776.

Cavoukian, Ann. 2012. "Privacy and Drones: Unmanned Aerial Vehicles." Privacy by
Design, Canada 1 (1):1-27.

Chaiken, S., A. Liberman, and A. H. Early. 1989. "Heuristic and Systematic Information Processing within and beyond the Persuasion Context." In Unintended Thought., edited by J. S. Uleman and J. A. Bargh, 212-52. New York: Guilford Press.

Chamata, Johnny Elie. 2016. "On the Adoption of Civil Drones: A Note for Entrepreneurs and Policymakers." In 4th Global Conference on Business \& Social Sciences. Dubai, 14-15 November. 2017. "Convergence of the Unmanned Aerial Industry." Theoretical Economics Letters 7 (2):175-86. https://doi.org/ 10.4236/tel.2017.72015.

Chao-jun, Li, Zhang Chun-ming, Chen Yan, Zuo Jia-xu, and Chen Jia-yun. 2013. "The Study on Safety Goals and Public Acceptance of Nuclear Power." Energy Procedia 39 (1). Elsevier B.V.:415-22. https://doi.org/10.1016/j.egypro. 2013.07.231.

Clarke, Roger. 2014a. "The Regulation of Civilian Drones' Impacts on Behavioural Privacy." Computer Law and Security Review 30 (3). Elsevier Ltd:286-305. https://doi.org/10.1016/j.clsr.2014.03.005.

. 2014b. "The Regulation of Civilian Drones' Impacts on Public Safety." Computer Law \& Security Review 30 (1): 263-85.

. 2014c. "Understanding the Drone Epidemic." Computer Law and Security Review 30 (3). Elsevier Ltd:230-46. https:// doi.org/10.1016/j.clsr.2014.03.002.

Clothier, Reece A., Dominique A. Greer, Duncan G. Greer, and Amisha M Mehta. 2015. "Risk Perception and the Public Acceptance of Drones." Risk Analysis 35 (6):1167-83. https://doi.org/10.1111/risa. 12330.

Costa-Font, M, and J M Gil. 2012. "MetaAttitudes and the Local Formation of Consumer Judgements towards Genetically Modified Foods." British Food Journal 114 (10):1463-85. https://doi.org/ 10.1108/00070701211263028. 
Costa-Font, Montserrat. 2013. "Understanding Food Scares: The Role of Ambiguity Aversion and Analogical Reasoning." Human \& Ecological Risk Assessment 19 (3):661-73. https://doi.org/ 10.1080/10807039.2012.685805.

Costa-Font, Montserrat, Jos?? M. Gil, and W. Bruce Traill. 2008. "Consumer Acceptance, Valuation of and Attitudes towards Genetically Modified Food: Review and Implications for Food Policy." Food Policy 33 (2):99-111. https://doi.org/ 10.1016/j.foodpol.2007.07.002.

Costa-Font, Montserrat, and Jose M. Gil. 2012. "Does Expert Trust and Factual Knowledge Shape Individual's Perception of Science?" International Journal of Consumer Studies 36 (6):668-77. https://doi.org/10.1111/j. 1470-6431.2011.01044.x.

Costa-Font, Montserrat, and José M. Gil. 2009. "Structural Equation Modelling of Consumer Acceptance of Genetically Modified (GM) Food in the Mediterranean Europe: A Cross Country Study." Food Quality and Preference 20 (6). Elsevier Ltd: 399-409. https://doi.org/10.1016/ j.foodqual.2009.02.011.

DailyMail. 2014. "The Ambulance Drone That Could Save Your Life: Flying Defibrillator Can Reach Speeds of 60mph." 2014. http://www. dailymail.co.uk/sciencetech/ article-2811851/The-ambulance-dronesave-life-Flying-defibrillator-reachspeeds-60mph.html.

Davis, F, R P Bagazzi, and P R Warshaw. 1989.

"User Acceptance of Computer Technology: A Comparison of Two Theoretical Models." Management Science 35 (8):982-1003. https://doi.org/10.1287/ mnsc.35.8.982.

Elias, Bart. 2012. "Pilotless Drones: Background and Considerations for Congress Regarding Unmanned Aircraft Operations in the National Airspace System." Congressional Research Service, 1-24. http://www.fas.org/sgp/crs/natsec/ R42718.pdf.

EUBusiness. 2014. "Remotely Piloted Aviation Systems, or Drones." 2014. http:// www.eubusiness.com/topics/transport/ drones/?searchterm=drone economy.

Eyerman, Joe, Clark Letterman, Wayne Pitts, and John Holloway. 2013. "Unmanned Aircraft and the Human Element: Public Perceptions and First Responder Concerns."

Fischhoff, Baruch, Paul Slovic, Sarah Lichtenstein, Stephen Read, and Barbara Combs. 1978. "How Safe Is Safe Enough A Psychomeric Study of Attitudes towards Technological Risks and Benefits." Policy Sciences 9 (2):127-52. https://doi.org/ 10.1007/BF00143739.

Frewer, L., J. Lassen, B. Kettlitz, J. Scholderer, V. Beekman, and K. G. Berdal. 2004. "Societal Aspects of Genetically Modified Foods." Food and Chemical Toxicology 42 (7):1181-93. https://doi.org/10.1016/j.fct. 2004.02.002.

Frewer, Lynn J., Ivo A. van der Lans, Arnout R H Fischer, Machiel J. Reinders, Davide Menozzi, Xiaoyong Zhang, Isabelle van den Berg, and Karin L. Zimmermann. 2013. "Public Perceptions of Agri-Food Applications of Genetic Modification - A Systematic Review and Meta-Analysis." Trends in Food Science and Technology 30 (2). Elsevier Ltd:142-52. https://doi.org/ 10.1016/j.tifs.2013.01.003.

Hossain, F., and others. 2002. "Uncovering Factors Influencing Public Perceptions of Food Biotechnology." Food Policy, no. June:1-31. http://ageconsearch.umn.edu/ bitstream/18178/1/wp02ho02.pdf.

Hossain, Ferdaus, Benjamin Onyango, Brian Schilling, William Hallman, and Adesoji Adelaja. 2003. "Product Attributes, Consumer Benefits and Public Approval of Genetically Modified Foods." International Journal of Consumer Studies 27 (November):353-365. https://doi.org/ 10.1046/j.1470-6431.2003.00303.x.

Huang, Lei, Jun Bi, Bing Zhang, Fengying Li, and Changsheng Qu. 2010. "Perception of People for the Risk of Tianwan Nuclear Power Plant." Frontiers of Environmental Science and Engineering in China 4 (1): 73-81. https://doi.org/10.1007/ 
s11783-009-0151-z.

Hwang, Yujong, Mohanned Al-Arabiat, and D.H. Shin. 2015. "Understanding Technology Acceptance in a Mandatory Environment: A Literature Review." Information Development 31 (3):1-18. https://doi.org/ 10.1177/0266666915593621.

Jenkins-Smith, Hank C., Carol L. Silva, Matthew C. Nowlin, and Grant deLozier. 2011. "Reversing Nuclear Opposition: Evolving Public Acceptance of a Permanent Nuclear Waste Disposal Facility." Risk Analysis 31 (4):629-44. https://doi.org/ 10.1111/j.1539-6924.2010.01543.x.

Jenkins, Darryl, and Bijan Vasigh. 2013. "The Economic Impact of Unmanned Aircraft Systems Integration in the United States." http://www.auvsi.org/econreport.

Khong, P C, E Holroyd, and W Wang. 2015. "A Critical Review of the Theoretical Frameworks and the Conceptual Factors in the Adoption of Clinical Decision Support Systems." Comput Inform Nurs 33 (12): 555-70. https://doi.org/10.1097/cin. 0000000000000196.

Kim, Younghwan, Minki Kim, and Wonjoon Kim. 2013. "Effect of the Fukushima Nuclear Disaster on Global Public Acceptance of Nuclear Energy." Energy Policy 61. Elsevier:822-28. https://doi.org/10.1016/ j.enpol.2013.06.107.

Legris, P., J. Ingham, and P. Collerette. 2003. "Why Do People Use Information Technology? A Critical Review of the Technology Acceptance Model." Information \& Management 40 (1):191204.

LeMieux, Jerry. 2014. Drone: UAV Dictionary. 1st ed. Unmanned Vehicle University.

Liberati, Alessandro, Douglas G. Altman, Jennifer Tetzlaff, Cynthia Mulrow, Peter C. Gøtzsche, John P A loannidis, Mike Clarke, P. J. Devereaux, Jos Kleijnen, and David Moher. 2009. "The PRISMA Statement for Reporting Systematic Reviews and Meta-Analyses of Studies That Evaluate Health Care Interventions: Explanation and Elaboration." Journal of
Clinical Epidemiology 62 (10):e1-34. https://doi.org/10.1016/j.jclinepi. 2009.06.006.

Liu, Changxin, Zuoyi Zhang, and Steve Kidd. 2008. "Establishing an Objective System for the Assessment of Public Acceptance of Nuclear Power in China." Nuclear Engineering and Design 238 (10):2834-38. https://doi.org/10.1016/j.nucengdes. 2008.04.001.

Lucht, Jan M. 2015. "Public Acceptance of Plant Biotechnology and GM Crops." Viruses 7 (8):4254-81. https://doi.org/10.3390/ v7082819.

Macsween-George, Sandra Lynn. 2003. "Will the Public Accept UAVs for Cargo and Passenger Transportation?" IEEE Aerospace Conference Proceedings 1:357-67. https://doi.org/10.1109/AERO. 2003.1235066.

Magnusson, Maria K, and Ulla-Kaisa Koivisto Hursti. 2002. "Consumer Attitudes towards Genetically Modified Foods." Appetite 39 (1):9-24. https://doi.org/10.1006/appe. 2002.0486 .

Mills, Mark P. 2016. "Drone Disruption: The Stakes, The Players, And The Opportunities." Forbes. 2016. https:// www.forbes.com/sites/markpmills/ 2016/03/23/drone-disruption-the-stakesthe-players-and-the-opportunities/ \#ed8a2fe7d0b5.

Molina, Pere, M. Pares Eulalia, Ismael Colomina, Teo Vitoria, Pedro Silva, Jan Skaloud, Wolfgang Kornus, Rafael Prades, and Carmen Aguilera. 2012. "Drones to the Rescue!" Unmanned Aerial Search, 2012.

Moon, Wanki, and Moon Balasubramanian. 2001. "A Multi-Attribute Model of Public Acceptance of Genetically Modified Organisms." In Annual Meeting of American Agricultural Economics Association, 1-19. Chicago.

Murphy, AJ, MJ Landamore, and RW Birmingham. 2008. "The Role of Autonomous Underwater Vehicles for Marine Search and Rescue Operations." International Journal of the Society for 
Underwater Technology 27 (4):195-205. https://doi.org/10.3723/ut.27.195.

Murray, Patrick. 2012. "U.S. Supports Some Domestic Drone Use."

Onyango, B, R M Nayga Jr., and B Schilling. 2004. "Role of Product Benefits and Potential Risks in Consumer Acceptance of Genetically Modified Foods." AgBioForum 7 (4):202-11. https://doi.org/ 10.1111/j.1470-6431.2004.00352.x.

Otway, Harry J., and Detlof Von Winterfeldt. 1982. "Beyond Acceptable Risk: On the Social Acceptability of Technologies." Policy Sciences 14 (3):247-56. https:// doi.org/10.1007/BF00136399.

Pidgeon, Thomas Edward, Georgina Wellstead, Harkiran Sagoo, Daniyal J. Jafree, Alexander J. Fowler, and Riaz A. Agha. 2015. "An Assessment of the Compliance of Systematic Review Articles Published in Craniofacial Surgery with the PRISMA Statement Guidelines: A Systematic Review." Journal of Cranio-Maxillofacial Surgery 44 (10). Elsevier Ltd:1522-30. https://doi.org/10.1016/j.jcms.2016.07.018.

Prochaska, J.O., C.A. Redding, and K.E. Evers. 2008. "The Transtheoretical Model and Stage of Change." In Health Behavior and Health Education: Theory, Research, and Practice, Fourth, 97-122. San Francisco: Wiley.

Rollin, Fanny, Jean Kennedy, and Josephine Wills. 2011. "Consumers and New Food Technologies." Trends in Food Science and Technology 22 (2-3). Elsevier Ltd:99111. https://doi.org/10.1016/j.tifs. 2010.09.001.

Sebbane, Yasmina Bestaoui. 2012. Lighter than Air Robots. 1st ed. Dordrecht: Springer Science + Business Media. https://doi.org/ 10.1007/978-94-007-2663-5.

Siegrist, M. 2000. "The Influence of Trust and Perceptions of Risk and Benefits on the Aceeptance of Gene Technology." Risk Analysis 20 (2): 195-203.

Siegrist, Michael. 2008. "Factors Influencing Public Acceptance of Innovative Food Technologies and Products." Trends in
Food Science and Technology 19 (11). Elsevier Ltd:603-8. https://doi.org/10.1016/ j.tifs.2008.01.017.

Siegrist, Michael, Marie Eve Cousin, Hans Kastenholz, and Arnim Wiek. 2007. "Public Acceptance of Nanotechnology Foods and Food Packaging: The Influence of Affect and Trust." Appetite 49 (2):459-66. https:// doi.org/10.1016/j.appet.2007.03.002.

Siegrist, Michael, Nathalie Stampfli, Hans Kastenholz, and Carmen Keller. 2008. "Perceived Risks and Perceived Benefits of Different Nanotechnology Foods and Nanotechnology Food Packaging." Appetite 51 (2):283-90. https://doi.org/ 10.1016/j.appet.2008.02.020.

Silva, Leiser. 2007. "Post-Positivist Review of Technology Acceptance Model." Journal of the Association for Information Systems 8 (4):255-66. http:// search. proquest.com.ezproxylocal. library. nova.edu/docview/198899196? accountid=6579\%5Cnhttp:// novacat.nova.edu:4550/resserv? genre $=$ unknown\&issn $=15369323 \&$ title $=\mathrm{Jo}$ urnal+of+the+Association+for+Information + Systems\&volume $=8 \&$ issue $=4 \&$ date $=200$ 7-04-01\&atitle= .

Sun, Chuanwang, Xiting Zhu, and Xiaochun Meng. 2016. "Post-Fukushima Public Acceptance on Resuming the Nuclear Power Program in China." Renewable and Sustainable Energy Reviews 62. Elsevier: 685-94. https://doi.org/10.1016/j.rser. 2016.05.041.

Tam, Alice. 2011. "Public Perception of Unmanned Aerial Vehicles."

Truelove, Heather Barnes, and Michael Greenberg. 2013. "Who Has Become More Open to Nuclear Power because of Climate Change?" Climatic Change 116 (2):389-409. https://doi.org/10.1007/ s10584-012-0497-2.

Tsujikawa, Norifumi, Shoji Tsuchida, and Takamasa Shiotani. 2016. "Changes in the Factors Influencing Public Acceptance of Nuclear Power Generation in Japan Since the 2011 Fukushima Daiichi Nuclear Disaster." Risk Analysis: An International 
Journa/ 36 (1):98-113. https://doi.org/

10.1111/risa.12447.

Veeman, Michele, Wiktor Adamowicz, and Wuyang Hu. 2005. "Project Report." Rural Economy.

Visschers, Vivianne H M, and Michael Siegrist. 2013. "How a Nuclear Power Plant Accident Influences Acceptance of Nuclear Power: Results of a Longitudinal Study Before and After the Fukushima Disaster." Risk Analysis 33 (2):333-47. https://doi.org/10.1111/j. 1539-6924.2012.01861.x.

Visschers, Vivianne H M, and Lasse Wallquist. 2013. "Nuclear Power before and after Fukushima: The Relations between Acceptance, Ambivalence and Knowledge." Journal of Environmental Psychology 36. Elsevier Ltd:77-86. https:// doi.org/10.1016/j.jenvp.2013.07.007.

Yang, Yuan-hua, Li Li, and Guo-hua Niu. 2013. "A Explanatory Model of Public Acceptance for Nuclear Power Technology: From Low-Carbon Perspective." In The 19th International Conference on Industrial Engineering and Engineering Management, edited by E. Qi et al., 423-31. Springerlink-Verlag. https:// doi.org/10.1007/978-3-642-38427-1_45.

Yankelovic, Daniel. 1991. Coming to Public Judgment: Making Democracy Work in a Complex World. New York: Syracuse University Press. 